\title{
Profile of Oncological Patients Needing Rehabilitation by Dental and Bucomaxillofacial Prostheses in a Brazilian Subpopulation
}

\section{Cristiane Loreda Garcia}

University of Cuiaba: Universidade de Cuiaba

Ivan Onone Gialain

University of Cuiaba: Universidade de Cuiaba

Maria Carmen Palma Faria Volpato

Mato Groso Cancer Hospital

Luiz Evaristo Ricci Volpato ( $D$ odontologiavolpato@uol.com.br)

University of Cuiaba: Universidade de Cuiaba https://orcid.org/0000-0002-2969-1963

\section{Research Article}

Keywords: Cancer, Dental Prosthesis,Epidemiology, Maxillofacial Prosthesis, Oral Rehabilitation

Posted Date: May 24th, 2021

DOI: https://doi.org/10.21203/rs.3.rs-519549/v1

License: (c) (i) This work is licensed under a Creative Commons Attribution 4.0 International License.

Read Full License 


\section{Abstract}

Purpose: This study aimed to identify the profile of cancer patients in need of rehabilitation with oral and/or buccomaxillofacial prostheses, as well as to evaluate the possible reasons for not concluding the rehabilitation.

Materials \& Methods: This is a retrospective observational study carried out at the Dentistry Department of the Mato Grosso Cancer Hospital, Cuiabá, MT, Brazil, through the evaluation of the medical records of patients attended from April 2017 to November 2019.

Results: The study population comprised 256 patients who met the research inclusion criteria. It was found that $30.90 \%$ of the patients were elderly, $65.6 \%$ were men, $70.3 \%$ brown, $27.3 \%$ retired, $49.2 \%$ married and $52 \%$ coming from municipalities of the interior of the state of Mato Grosso. From the total of patients, $67.23 \%$ reported smoking and $53.9 \%$ alcohol consumption. As for the location of the tumor, $57.4 \%$ had it in the head and neck region, $55.1 \%$ of which were epidermoid carcinoma and in $28.9 \%$ of cases the disease stage was IV. Most of the patients (60.2\%) completed prosthetic rehabilitation, with total prostheses predominating. The main reasons for not completing the rehabilitation were the patient's death and weakness.

Conclusions: Patients who started treatment in more advanced stages of cancer had a greater chance of not completing the prosthetic rehabilitation, and the incompletion of rehabilitation treatment was directly related to the patients' death and the state of weakness.

\section{Introduction}

Cancers in the head and neck region profoundly affect the quality of life of patients, as they can affect the patient's aesthetics and are a constant reminder of the disease. These cancers are emotionally debilitating for patients and their families ${ }^{1}$.

The diagnosis of cancer negatively impacts the patient's life and feelings of fear and suffering are common throughout the process, which begins with the diagnostic phase, followed by therapy and survival ${ }^{2,3}$. Most post-treatment patients, whether surgical or not, remain in subsequent follow-up visits for an average period of 10 years ${ }^{4}$.

Cancer treatment causes from mild to more severe adverse effects ${ }^{5}$. Large facial defects compromise vital functions such as breathing, chewing, speaking, swallowing and aesthetics. A prosthetic reconstruction of facial defects helps to restore functional disabilities and assists in the recovery of the patient and his family ${ }^{6}$. 
In the treatment of tumors in the head and neck region, patients are also often submitted to surgeries that have a serious impact on quality of life and can impair appearance and functional characteristics ${ }^{7}$. Mutilations on the face can bring very important aesthetic and functional damage to patients, causing morphofunctional and psychosocial changes leading the individual to social and family isolation. Thus, it is imperative that health professionalscommit to their rehabilitation ${ }^{8}$.

Prosthetic treatment is indicated to regain lost oral functions, improve physical appearance and enable patients to participate in daily activities with greater confidence ${ }^{9}$. The absence of teeth, not replaced by prosthesis also negatively affects the quality of life of cancer patients ${ }^{10}$.

Given the important demand for dental care of patients with malignant neoplasms and the positive impact of rehabilitation on their quality of life, this study aims to outline the profile of cancer patients rehabilitated with dental and/or maxillofacial prostheses, and also the reasons for inconclusion of rehabilitation treatments.

\section{Materials \& Methods}

\section{Population selection}

Data collection was performed by surveying the medical records of patients treated at the Dentistry Department of the Cancer Hospital of Mato Grosso, Cuiabá, MT, Brazil, from April 2017 to November 2019. This period was selected because the hospital uses a single medical record for each patient and the medical records are managed by an information system that was replaced in April 2017.

All prosthetic care performed in the period were surveyed in the Care Management System, reaching the total of patients who had an indication for prosthetic rehabilitation treatment in the period. Patients of both sexes and of any age were included. Patients who were rehabilitated but had no confirmed diagnosis of cancer and patients whose information was not possible to be collected in the respective medical records were excluded.

Collected data

Information about age; sex; race/color of skin (defined through the recommendation by the Brazilian Institute of Geography and Statistics - IBGE) ${ }^{11}$; origin (separated into two distinct groups: state capital and cities from the interior of the state); profession; marital status; smoking and drinking habits; and family history of cancer were collected.

As for the characteristics of the disease, the tumor location, histological type, stage of the disease, and the cancer treatments performed (surgery, radiotherapy and chemotherapy) were collected. Regarding the characteristics of prosthetic rehabilitation, data were collected regarding the types of maxillary prostheses (total, partial, total obturator, and partial obturator), mandibular (total or partial), and facial; and the reasons for not completing rehabilitation. 
Patients who met the inclusion criteria, but whose medical records did not present the information on completing the rehabilitation or installation of the prosthesis, were actively sought by telephone and questioned as to the reason for the fail in the conclusion of the rehabilitation treatment. Those patients or their relatives contacted, gave different answers to the fail in the conclusion of the treatment. These responses were grouped into five distinct groups, as follows: patient died before completing the rehabilitation treatment; patient interrupted the treatment because of weakness; patient is still in rehabilitation treatment; patient completed the rehabilitation in somewhere else and patients with no defined response (corresponding to the cases in which telephone contact was unsuccessful).

Data analysis

A single researcher collected the data and organized in an Excel spreadsheet. Descriptive statistical analysis was performed for the studied variables. The result was presented as absolute and relative frequencies. To analyze possible associations between independent variables and the dependent variable not completing the prosthesis and between the independent variables and the dependent variables reason for not completing the prosthesis, multinominal logistic regression was applied, following previously used methodology ${ }^{12}$. Statistical tests were performed using the SPSS version 22.0 program and results of $p<0.05$ were considered significant.

This study was approved by the Human Research Ethics Committee of the University of Cuiabá (UNIC), protocol \#3.740.742.

\section{Results}

In the present study, 470 hospital records were analyzed, among which 256 records fit the research inclusion criteria. The other patients were rehabilitated, but were excluded because they had no confirmed diagnosis of cancer or the information was not possible to be collected in the respective medical records.

The distribution of patients according to demographic characteristics, smoking and drinking habits and family history of cancer are shown in Table 1. The distribution of patients according to the treatment and characteristics of the tumor is shown in Table 2.

Figure 1 shows the flowchart of the characteristics of prosthetic rehabilitation and reasons for not completing the prosthetic treatment.

The analysis of the association between age, marital status, city of origin and cancer staging with the completion of the prosthesis using multivariate logistic regression is shown in Table 3. The association between the stage of cancer and the reason for not performing the prosthesis using multivariate logistic regression is shown in Table 4.

\section{Discussion}


Cancer patients rehabilitated with dental and/or maxillofacial prostheses are elderly and the main reason for not concluding the treatment was the patient's death. The population studied was predominantly of married and retired men. As for the origin $52 \%$ of the patients are from cities in the interior of the state and $70.3 \%$ of the patients are brown. Caetano et al. ${ }^{13}$,evaluated the quality of life, body image and selfesteem in patients with sequelae after treatment of head and neck cancer, candidates for prosthetic rehabilitation. They had a sample of 10 patients, and also found a predominance of male patients (60\%); $50 \%$ married; $30 \%$ aged 51 to 60 years, $40 \%$ farmer, $30 \%$ retired; $60 \%$ were from the interior of the state.

In a study by Rettig and D'Souza ${ }^{14}$, they mention that two of the main causes of head and neck cancer are the use of tobacco and alcohol. Gomes et al. ${ }^{15}$, analyzed 33 patients, where $84.38 \%$ and $87.50 \%$ of the individuals used or were still in use of tobacco and alcohol respectively.

The most affected anatomical sites by the tumors in this population were head/neck (57.4\%), breast $(12.1 \%)$ and prostate $(10.3 \%)$. Breast and prostate cancer are among the most prevalent in Brazil ${ }^{16}$,the greater number of patients with tumors in the head and neck in this study can be explained because these patients always have their oral health analyzed in the Dentistry Department before starting the anitineoplastic treatment and, with that, they already establish a connection, returning later for oral rehabilitation.

The most frequent histopathological diagnosis was epidermoid carcinoma with 141 cases $(55.1 \%)$ and the most frequent disease staging was IV with 74 cases (28.9\%). Epidermoid carcinoma is the most frequent malignancy among tumors in the head and neck region and the sixth most common cancer worldwide ${ }^{17}$.

Of the population studied, 154 patients $(60.2 \%)$ completed their rehabilitation with dental prostheses, including 3 facial prostheses, 148 maxillary prostheses, including 11 obturators, and 126 mandibular prostheses. Quispe et al. ${ }^{18}$, evaluated 75 individuals, but of this group only 30 were cancer patients. The research assessed the need for maxillary and mandibular prostheses, the data collected were: 21 patients needed a maxillary prosthesis: to replace one element (10\%), to replace more than one element (33.3\%), needs prosthesis combination (13.3\%) total prosthesis (13.7\%); 29 patients used mandibular prosthesis: to replace more than one element $(70 \%)$, required the combination of prostheses $(3.3 \%)$, total prosthesis (23.7\%). Joo et al. ${ }^{7}$, cites in his research that patients undergoing oncological treatments may have several sequelae, impairing masticatory function, swallowing, aesthetics, so the use of total or partial obturator prosthesisis an alternative to remedy such sequelae and enable a better quality of life for the patient Parameswari et al. ${ }^{19}$ also concluded in their research that prosthetic rehabilitation with obturator prosthesis restores the missing intraoral structures and acts as an anatomical barrier between the oral and nasal cavities, restoring function and aesthetics.

The study was carried out at the Cancer Hospital of Mato Grosso, located in the city of Cuiabá, MT. The Cancer Hospital of Mato Grosso uses a unique medical record for each patient, regardless of the treatments that are performed in different departments of the institution. When working with the medical 
records, there was a lack of relevant information. The absence of this information impaired the analysis and represents a limitation of this study. This limitation is often found in studies that work with secondary databases, which were not collected specifically for research. However, it is compensated by the possibility of providing information on a large number of patients quickly and agile over an extended period of time ${ }^{20}$.

\section{Conclusion}

The patient rehabilitated with dental and maxillofacial prostheses is mainly male, elderly, brown, married, from cities in the interior of the state, smoker and alcoholic with a history of cancer in the family. They had cancer in the head and neck, the epidermoid carcinoma type, in stage IV and underwent surgery, radiotherapy and chemotherapy. The most performed prostheses were total. The main reasons for not completing the rehabilitation were the patient's death and weakness. Patients who started treatment in more advanced stages of cancer had a greater chance of not completing prosthetic rehabilitation, and had the inconclusion of rehabilitation treatment related to death and weakness.

\section{Declarations}

Funding: None to declare.

Conflicts of interest/Competing interests: None to declare.

Ethics approval: This study was approved by the Human Research Ethics Committee of the University of Cuiabá (UNIC), protocol \#3.740.742.

Consent to participate: Yes.

Consent for publication: Yes.

Availability of data and material: Not applicable.

Code availability: Not applicable.

Authors' contributions: All authors have made substantial contributions to conception and design, acquisition of data, analysis and interpretation of data. All authors participated on drafting the article or revising it critically for important intellectual content. All authors approved of the version to be published and all subsequent versions.

\section{References}

1. Lemon JC, Kiat-amnuay S, Gettleman L, et al: Facial prosthetic rehabilitation: preprosthetic surgical techniques and biomaterials. Curr Opin Otolaryngol Head Neck Surg. 2005;13:255-262. 
2. Ness S, Kokal J, Fee-Schroeder K, et al: Concerns across the survivorship trajectory: results from a survey of cancer survivors. Oncol Nurs Forum. 2013;40:35-42.

3. Krakow MC, Girardon-Perlini CMO, Stamm B, et al: Experience of families facing the revelation of the cancer diagnosis in one of its integrants. Rev Min Enferm. 2015;19:747-775.

4. Lopes JV, Bergerot CD, Barbosa LR, et al: Impact of breast cancer and quality of life of women survivors. Rev. Bras. Enferm. 2018;71:2916-2921.

5. Costa AC, Silva GC, Silva Filho OFS, et al: Acupuncture in support chemotherapy treatment: an integrative review. R. Interd. 2017;10:180-191.

6. Vickery LE, Latchford G, Hewison J, et al: The impact of head and neck cancer and facial disfigurement on the quality of life of patients and their partners. Head Neck 2003;2013:289-296

7. Joo YH, Cho JK, Koo BS, et al: Guidelines for the Surgical Management of Oral Cancer: Korean Society of Thyroid-Head and Neck Surgery. Clin Exp Otorhinolaryngol. 2019;12:107-144.

8. Volpato LE, Kloster AP, Nunes LF, et al: Cariogenic microbiota of children under chemotherapy: A pilot study. J Indian Soc Pedod Prev Dent. 2016;34:370-376.

9. Cotic J, Jamsek J, Kuhar M, et al: Implant-prosthetic Rehabilitation After Radiation Treatment in Head and Neck Cancer Patients: A Case-Series Report of Outcome. Radiol Oncol. 2016;51:94-100.

10. Romeo U, Lollobrigida M, Palaia G, et al: Soft tissue management and prosthetic rehabilitation in a tongue cancer patient. Case Rep Dent. 2013;2013:475186.

11. Petruccelli JL, Saboia AL (org.) ethnic-racial characteristics of the population: classifications and identities. Rio de Janeiro: IBGE, 2013.

12. Flores-Ruiz R, Castellanos-Cosano L, Serrera-Figallo MA, et al: Evolution of oral cancer treatment in na andalusian population sample: Rehabilitation with prosthetic obturation and removable partial prosthesis. J Clin Exp Dent. 2017;9:e1008-e1014.

13. Caetano RDS, Volpato LER, Castro PHS, et al: Smoking influences the Occurrence of Radiodermatitis in Head and Neck-irradiated Patients. WJD. 2017;8:55-58.

14. Rettig EM, D'Souza G. Epidemiology of head and neck cancer. Surg Oncol Clin N Am. 2015;24:379396.

15. Gomes EPAA, Aranha AMF, Borges AH, et al: Head and Neck Cancer Patients' Quality of Life: Analysis of Three Instruments. J Dent (Shiraz). 2020;21:31-41.

16. Jethwa AR, Khariwala SS. Tobacco-related carcinogenesis in head and neck cancer. Cancer Metastasis Rev. 2017;36:411-423.

17. Lacko M, Braakhuis BJ, Sturgis EM, et al: Genetic susceptibility to head and neck squamous cell carcinoma. Int J Radiat Oncol Biol Phys. 2014;89:38-48.

18. Quispe RA, Cremonesi AL, Gonçalves JK, et al: Case-control study of oral disease indexes in individuals with head and neck cancer after antineoplastic therapy. Einstein. 2018;16:eAO4245.

19. Parameswari BD, Rajakumar M, Jagadesaan N, et al: Case Presentation of Two Maxillectomy Patients Restored with Two-piece Hollow Bulb Obturator Retained using Two Different Types of 
Magnets. J Pharm Bioallied Sci. 2017;9:S252-S256.

20. Volpato LER, Scatena JH. Analysis of the oral health policy of Cuiabá Municipality, Mato Grosso State, Brazil, using the outpatient Information System database of the national Public Health System (SIA-SUS). Epidemiol. Serv. Saúde . 2006;15:47-55.

\section{Tables}

Table 1. Distribution of patients according to demographic characteristics, smoking and drinking habits and family history of cancer $(n=256)$. 


\begin{tabular}{|c|c|c|c|}
\hline Variable & Groups & $\mathbf{N}$ & $\%$ \\
\hline \multirow[t]{5}{*}{ Age group } & $30-40$ years & 7 & 2.7 \\
\hline & $41-50$ years & 32 & 12.5 \\
\hline & $51-60$ years & 74 & 28.9 \\
\hline & $61-70$ years & 79 & 30.9 \\
\hline & $>70$ years & 64 & 25.0 \\
\hline \multirow[t]{2}{*}{ Sex } & Male & 168 & 65.6 \\
\hline & Female & 88 & 34.4 \\
\hline \multirow[t]{6}{*}{ Race/color of skin } & Brown & 180 & 70.3 \\
\hline & White & 43 & 16.8 \\
\hline & Black & 23 & 9.0 \\
\hline & Yellow & 4 & 1.6 \\
\hline & Indigenous & 2 & 0.8 \\
\hline & Not declared & 4 & 1.6 \\
\hline \multirow[t]{2}{*}{ City of origin } & State capital & 123 & 48.0 \\
\hline & Interior of state & 133 & 52.0 \\
\hline \multirow[t]{7}{*}{ Profession } & Retired & 70 & 27.3 \\
\hline & Housework & 38 & 14.8 \\
\hline & Self employed & 15 & 5.9 \\
\hline & Rural worker & 12 & 4.7 \\
\hline & Bricklayer & 10 & 3.9 \\
\hline & Other & 53 & 20.7 \\
\hline & Not declared & 58 & 22.7 \\
\hline \multirow[t]{5}{*}{ Marital status } & Single & 78 & 30.5 \\
\hline & Married & 126 & 49.2 \\
\hline & Divorced & 17 & 6.6 \\
\hline & Widow(er) & 16 & 6.3 \\
\hline & Not declared & 19 & 7.4 \\
\hline Smoking habit & Yes & 172 & 67.2 \\
\hline
\end{tabular}




\begin{tabular}{|llll|} 
& No & 80 & 31.3 \\
\cline { 2 - 4 } Alcohol consumption & Not declared & 4 & 1.6 \\
& Yes & 138 & 53.9 \\
\cline { 2 - 4 } & No & 113 & 44.1 \\
\cline { 2 - 4 } Family history of cancer & Not declared & 5 & 2.0 \\
\cline { 2 - 4 } & Yes & 130 & 50.8 \\
\cline { 2 - 4 } & No & 114 & 44.5 \\
\cline { 2 - 4 } & Not declared & 12 & 4.7 \\
\cline { 2 - 4 } & & \multicolumn{2}{|c}{}
\end{tabular}

Table 2. Distribution of patients according to tumor characteristics (location, histological type, staging) and cancer treatments performed (surgery, radiotherapy and chemotherapy) $(n=256)$. 


\begin{tabular}{|c|c|c|c|}
\hline Variable & Groups & $\mathbf{N}$ & $\%$ \\
\hline \multirow[t]{6}{*}{ Tumor location } & Head and neck & 147 & 57.4 \\
\hline & Breast & 31 & 12.1 \\
\hline & Prostate & 26 & 10.2 \\
\hline & Digestive system & 22 & 8.6 \\
\hline & Other & 26 & 10.2 \\
\hline & Not declared & 4 & 1.6 \\
\hline \multirow[t]{6}{*}{ Histological type } & Epidermoid carcinoma & 141 & 55.1 \\
\hline & Ductal carcinoma & 23 & 9.0 \\
\hline & Adenocarcinoma & 45 & 17.6 \\
\hline & Non-Hodgkin lymphoma & 9 & 3.5 \\
\hline & Other & 26 & 10.2 \\
\hline & Not declared & 12 & 4.7 \\
\hline \multirow[t]{5}{*}{ Staging } & 1 & 9 & 3.5 \\
\hline & II & 23 & 9.0 \\
\hline & III & 46 & 18.0 \\
\hline & IV & 74 & 28.9 \\
\hline & Not declared & 104 & 40.6 \\
\hline \multirow[t]{2}{*}{ Surgery } & Yes & 180 & 70.3 \\
\hline & No & 76 & 29.7 \\
\hline \multirow[t]{2}{*}{ Radiotherapy } & Yes & 182 & 71.1 \\
\hline & No & 74 & 28.9 \\
\hline \multirow[t]{2}{*}{ Chemotherapy } & Yes & 162 & 63.3 \\
\hline & No & 94 & 36.7 \\
\hline
\end{tabular}

Table 3. Analysis of the association of age, marital status, city of origin and cancer staging with the conclusion of the prosthesis using multivariate logistic regression. 


\begin{tabular}{|lllll|}
\hline Explanatory variable & B & $\boldsymbol{P}$ & Odds Ratio & IC 95\% \\
\hline Age & -0.214 & 0.214 & 0.807 & $0.576-1.132$ \\
\hline Staging & -0.425 & $\mathbf{0 . 0 4 8}$ & 1.530 & $1.003-2.333$ \\
\hline City of origin & 0.017 & 0.962 & 1.017 & $0.497-2.082$ \\
\hline Marital status & 0.662 & 0.078 & 1.938 & $0.928-4.050$ \\
\hline
\end{tabular}

* Overall chi-square $=9.095$ with $4^{\circ}$ degrees of freedom and $p=0.059$.

Table 4. Analysis of the association of age, city of origin and cancer stage with the reason for not completing the prosthesis using multivariate logistic regression.

\begin{tabular}{|llllll|}
\hline Category & Explanatory variable & B & $\boldsymbol{p}$ & Odds Ratio & IC 95\% \\
\hline Without defined reason & Staging & -0.449 & 0.525 & 0.638 & $0.160-2.544$ \\
\cline { 2 - 6 } & City of origin & -0.046 & 0.955 & 0.955 & $0.194-4.698$ \\
\cline { 2 - 6 } Debilitated patient & Age & -0.163 & 0.637 & 0.850 & $0.431-1.673$ \\
& Staging & -1.128 & 0.041 & 0.324 & $0.110-0.953$ \\
\cline { 2 - 6 } In treatment & City of origin & 1.176 & 0.101 & 3.241 & $0.794-13.23$ \\
\cline { 2 - 6 } & Age & 0.079 & 0.794 & 1.083 & $0.597-1.961$ \\
\hline Staging & -1.032 & 0.074 & 0.356 & $0.115-1.107$ \\
\hline Finished somewhere else & City of origin & 0.244 & 0.742 & 1.277 & $0.298-5.465$ \\
\cline { 2 - 6 } & Age & -0.224 & 0.480 & 0.799 & $0.429-1.489$ \\
\cline { 2 - 6 } & Staging & -2.073 & 0.007 & 0.126 & $0.028-0.563$ \\
\cline { 2 - 5 } & City of origin & 0.243 & 0.869 & 1.275 & $0.070-23.15$ \\
\cline { 2 - 5 } & Age & -0.952 & 0.106 & 0.386 & $0.122-1.224$ \\
\cline { 2 - 5 } & Age & & &
\end{tabular}

* Overall chi-square $=20.483$ with $12^{\circ}$ of freedom and $p=0.058$.

\section{Figures}




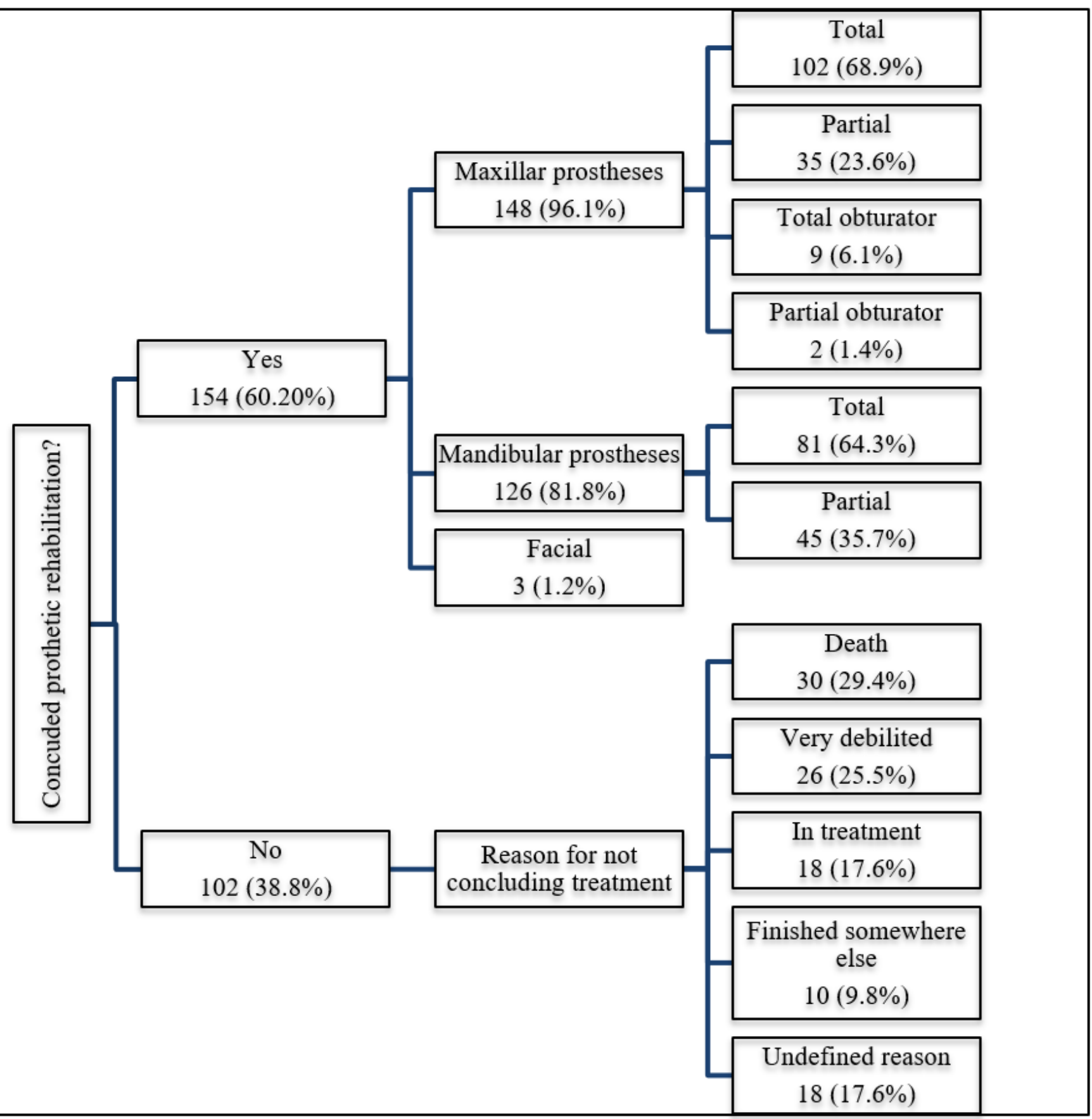

Figure 1

Flowchart of prosthetic rehabilitation characteristics and reasons for not completing the prosthetic treatment. 